\title{
Chapter 9 \\ Wetland Paddy Fields as Green \\ Infrastructure Against Flood
}

\author{
Yasunori Muto and Ryo Yokokawa
}

\begin{abstract}
Inundation simulation was carried out for an inland depression mainly covered by paddy fields to estimate its flood retention volume. In addition to surface water flooding, river flooding combined with it was also explored in a wide range of precipitation including a 1000-year return period. The results showed that the paddy fields in the studied area can retain approximately $60 \%$ of the total inundation volume. Judging from the relationship between the flood retention volume in the paddy fields and the number of inundated buildings above floor level, we could estimate two reference values regarding the potential volume of floodwater retention in paddy fields: one at which damage to the buildings starts to appear and the other where damage seriously expands in the main residential area. By using these reference values, we demonstrated the importance of land-use strategies in flood alleviation. In other words, by transferring buildings inundated between these levels to safer places, the potential volume of floodwater retention in paddy fields can be increased to a higher level, which well agrees with the concept of green infrastructure. The idea of flood alleviation deduced from this study can be applied to similar near-shore depressions cut off by sand dunes, which are common in Japan.
\end{abstract}

Keywords Wetland paddy fields · Flood retention · Surface water flooding · River flooding $\cdot$ Combined flooding

\footnotetext{
Y. Muto $(\square)$

Research Center for Management of Disaster and Environment, Tokushima University, Tokushima, Japan

Department of Civil and Environmental Engineering, Graduate School of Technology, Industrial and Social Sciences, Tokushima University, Tokushima, Japan

e-mail: muto_yas@ce.tokushima-u.ac.jp

R. Yokokawa

Water and Land Sector, CTI Engineering Co., Ltd., Osaka, Japan

e-mail: ry-yokokawa@ctie.co.jp
}

F. Nakamura (ed.), Green Infrastructure and Climate Change Adaptation, Ecological Research Monographs, https://doi.org/10.1007/978-981-16-6791-6_9 


\subsection{Introduction}

Paddy fields are well known to have many functions as green infrastructure, including flood risk reduction, water resources conservation, food production for both humans and animals, landscape improvement, community maintenance through agricultural activities, etc. (Ministry of the Environment, Japan 2016). As for flood risk reduction, although this has been pointed out qualitatively in early days (e.g. Masumoto 1998), there are few studies that quantitatively evaluate the flood control capacity of paddy fields. Recently in Japan, the so-called tambo-dam, using an orifice plate in a drain to improve the flood control volume of paddy fields, has been widely explored and has been adopted in some places (e.g. Yoshikawa et al. 2010). However, in contrast to such a micro device, exploring the macro function of paddy fields to floods, in connection with land-use planning, is still not popular.

From another aspect, owing to recent advances in numerical simulation techniques, inundation simulation models have been widely applied to urban flooding and have been proven to reproduce well flooding processes of surface water flooding (e.g. Thang et al. 2004). Such models can also be applied to wetlands to evaluate their flood control capacity through inundated volume and its time variation (e.g. Miyazu et al. 2012). However, most of the simulations considered surface water flooding and river flooding separately. Since a drainage network system consists of channels of various sizes, from small streams to large rivers, irrespective of either urban or rural areas, their design flood levels are different according to the channel size. In other words, particularly in a low and depressed area, flooding is likely to start from a small stream due to surface water flooding, and then inundation by river flooding from a larger river is combined.

Based on these exposed points, we conducted inundation simulations for an inland depression. The studied area is a small plain near the sea, cut off by sand dunes and presumably used to be a lagoon. Lower areas are mainly used as paddy fields and residential areas are located in higher places. Such topography and land use are typically seen along the shore in Japan (Kusaka 2020); thus, it is valuable to highlight the inundation characteristics of the area. The outputs will be anticipated to show a standard for flood alleviation measures in such areas.

\subsection{Studied Area}

The studied area is located in the southern part of Tokushima Prefecture, Japan (see Fig. 9.1). It is surrounded by the Osato beach (East), Kaifu River (South) and a mountainous area (North and West), and forms a depression of $2.86 \mathrm{~km}^{2}$ in an inland area. The elevation of the studied area is shown in Fig. 9.2 in terms of the altitude distribution drawn from the 5-m mesh DEM data. As shown in the figure, the eastern part along the beach is relatively higher because of geological sand dunes; thus, the inland part, even away from the beach, is lower than the dunes. The lowest parts are 


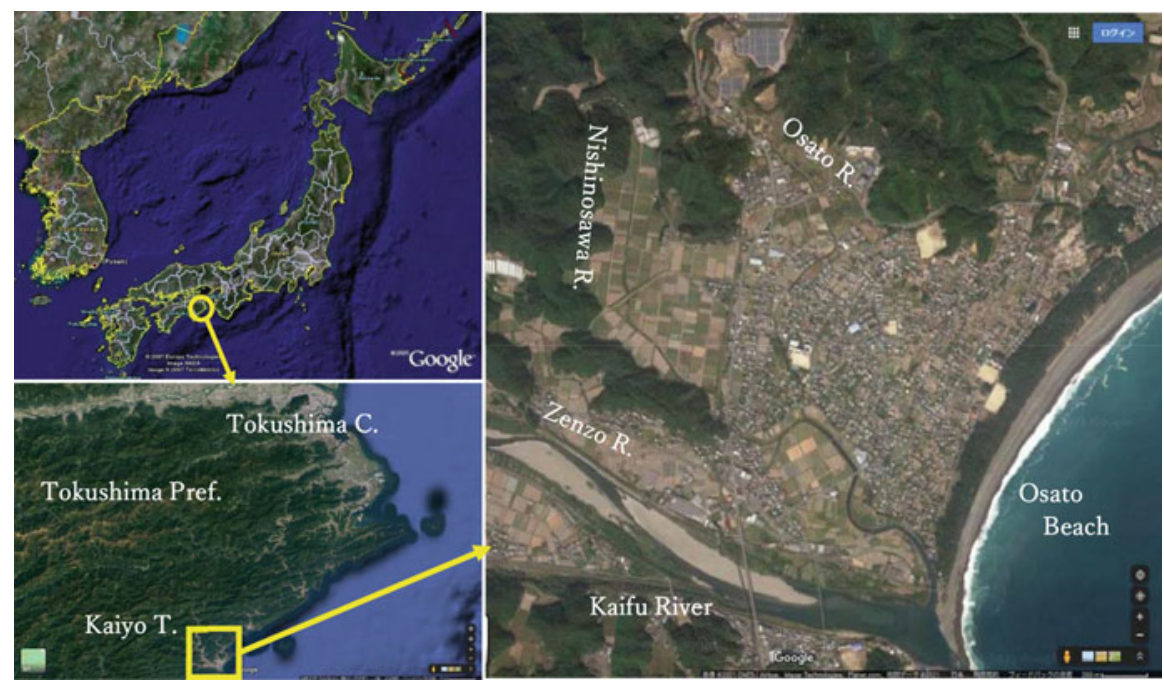

Fig. 9.1 The studied area: the Zenzo, Osato and Nishinosawa rivers basin, Tokushima, Japan

located along the three small streams, the Zenzo, Osato and Nishinosawa rivers. The land-use classification for the same mesh size is shown in Fig. 9.3. Nearly 35\% of the area is utilised as paddy fields, mainly in the lower western and southern parts. The three streams together with irrigation channels that spread over the wetland are eventually connected to the Kaifu River, and build a network drainage system for the area. In this study, the downstream boundary of the simulation area was set at the confluence point of the Kaifu River. Although floodgates are set at the confluence, they are open in normal time; thus, the water level in the streams is affected by the tide level through the Kaifu River and the confluence, particularly in their downstream reaches. During floods in the Kaifu River, floodgates are closed and a pump of $5 \mathrm{~m}^{3} / \mathrm{s}$ is operated for drainage when the water level in the Zenzo River exceeds a certain value.

\subsection{Inundation Simulation}

\subsubsection{Simulation Model}

A commercial inundation simulation software, AFREL (ㅇ NITA Consultant Co., Ltd. n.d.), was employed in this study. As shown in Fig. 9.4, AFREL can treat not only the surface flow but channel and pipe networks for sewerage overlapped on the surface. Moreover, flow exchanges among these three forms (surface, channel and sewerage pipe flows) can also be simulated; therefore, both inundation into the drainage and flooding from a river into the ground surface can be considered. In the 


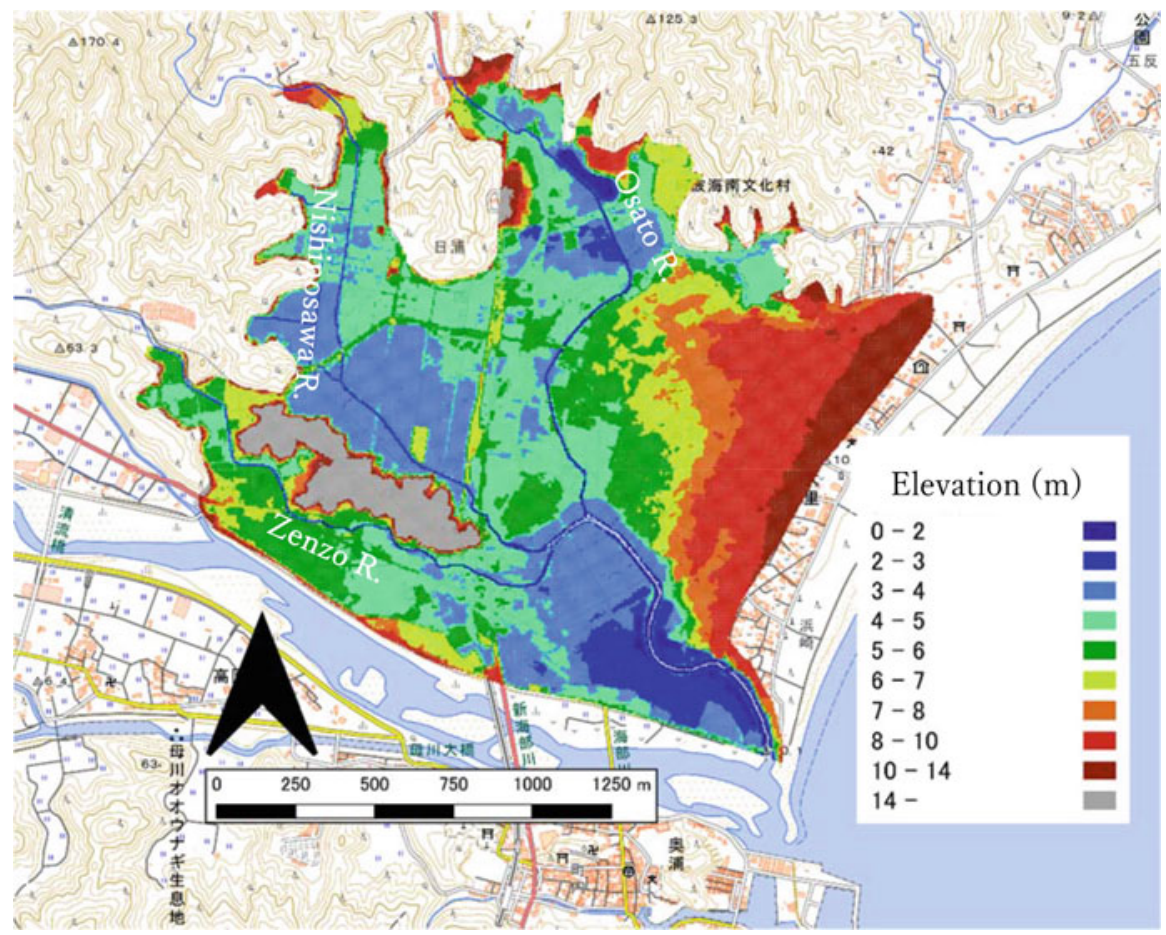

Fig. 9.2 The elevation of the studied area

studied area, a sewerage pipe network is not installed; thus, it was omitted in the simulation.

The governing equations for the 2-D surface flow based on Iwasa and Inoue (1982) are as follows:

$$
\begin{gathered}
\frac{\partial h}{\partial t}+\frac{\partial M}{\partial x}+\frac{\partial N}{\partial y}=r(t)+q_{C H}+q_{S W} \\
\frac{\partial M}{\partial t}+\frac{\partial}{\partial x} u M+\frac{\partial}{\partial y} v M=-g h \frac{\partial H}{\partial x}-\frac{\tau_{b x}}{\rho} \\
\frac{\partial N}{\partial t}+\frac{\partial}{\partial x} u N+\frac{\partial}{\partial y} v N=-g h \frac{\partial H}{\partial y}-\frac{\tau_{b y}}{\rho} \\
\frac{\tau_{b x}}{\rho}=\frac{g n^{2} M \sqrt{u^{2}+v^{2}}}{h^{4 / 3}}, \quad \frac{\tau_{b y}}{\rho}=\frac{g n^{2} N \sqrt{u^{2}+v^{2}}}{h^{4 / 3}}
\end{gathered}
$$

The governing equations for the channel flow are basically the same as those for the surface flow but omitting the advection terms in the momentum equations, as 


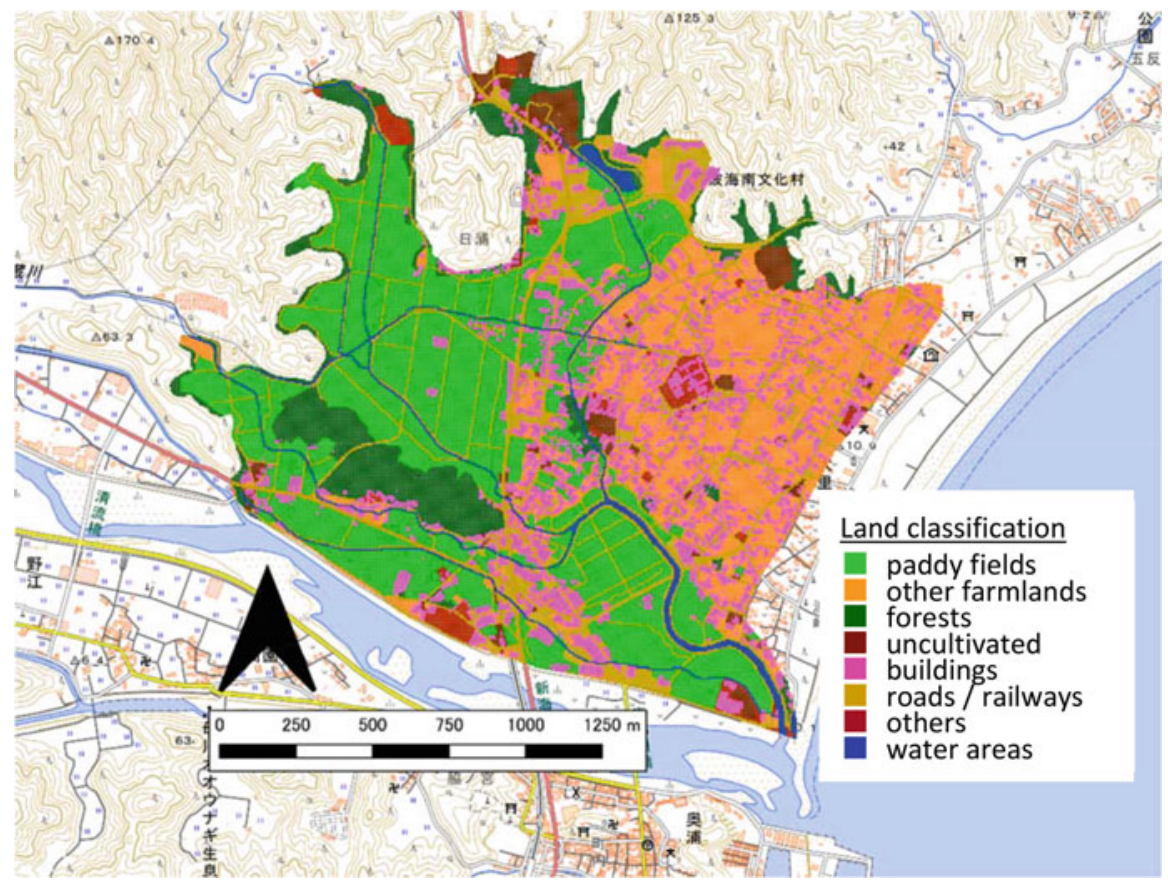

Fig. 9.3 The land-use classification of the studied area

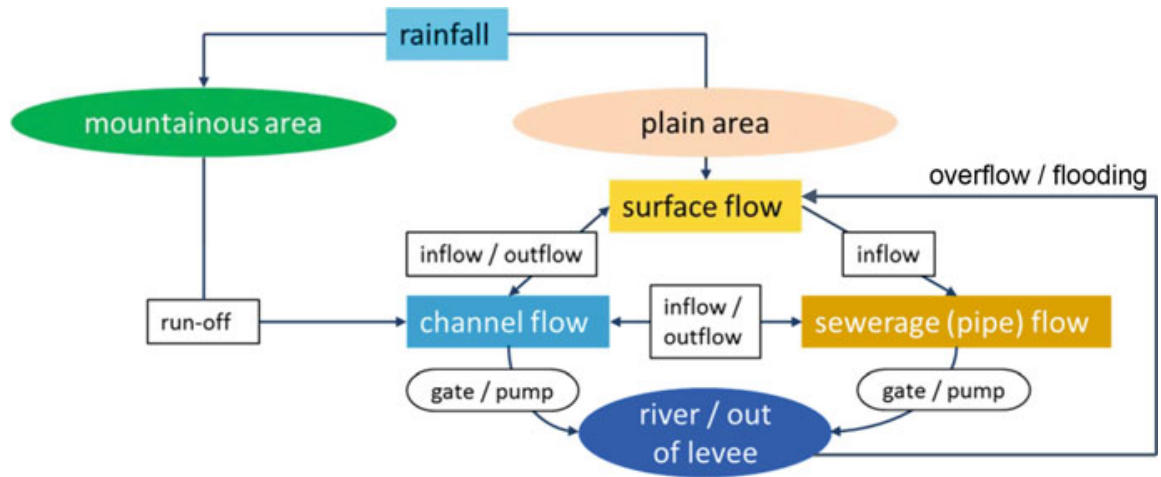

Fig. 9.4 Structure of the inundation simulation model, AFREL (CNITA Consultant Co., Ltd. n.d.)

follows:

$$
\begin{gathered}
\frac{\partial h}{\partial t}+\frac{\partial q_{x}}{\partial x}+\frac{\partial q_{y}}{\partial y}=q_{G R}+q_{S W} \\
\frac{\partial q_{x}}{\partial t}=-g h \frac{\partial H}{\partial x}-\frac{\tau_{x}}{\rho}
\end{gathered}
$$


Table 9.1 Roughness coefficients and infiltration coefficients adopted in this study

\begin{tabular}{l|l|l}
\hline Land-use type & Roughness coefficient & Infiltration coefficient \\
\hline Paddy fields & 0.060 & 0.70 \\
\hline Other farmlands & 0.050 & 0.60 \\
\hline Forests & 0.060 & 0.60 \\
\hline Uncultivated & 0.050 & 0.20 \\
\hline Buildings & 0.050 & 0.80 \\
\hline Roads/railways & 0.047 & 0.85 \\
\hline Others & 0.050 & 0.80 \\
\hline Water areas & 0.030 & 1.00 \\
\hline
\end{tabular}

$$
\begin{gathered}
\frac{\partial q_{y}}{\partial t}=-g h \frac{\partial H}{\partial y}-\frac{\tau_{x y}}{\rho} \\
\frac{\tau_{x}}{\rho}=\frac{g n^{2} R_{x}^{1 / 3}\left|q_{x}\right| q_{x}}{h^{2}}, \frac{\tau_{x y}}{\rho}=\frac{g n^{2} R_{y}{ }^{1 / 3}\left|q_{y}\right| q_{y}}{h^{2}}
\end{gathered}
$$

where $q_{C H}, q_{S W}$ and $q_{G R}$ are the interacting discharges with the channel, sewerage pipe and ground surface, respectively. $q_{x}$ and $q_{y}$ are defined at the same grid point as those for $M, N$ and $h$.

These equations are numerically solved explicitly on the staggered grid in space, and by the leapfrog method in time. Runoff discharge from the surrounding mountainous areas of $2.78 \mathrm{~km}^{2}$ is estimated by the rational method and given at the upstream end of a channel connected to the relevant mountain stream. Table 9.1 shows the roughness coefficients and infiltration coefficients adopted here in accordance with land-use classification.

\subsubsection{Precipitation and River Discharge Setting}

The model hyetograph was generated based on the records at the nearest observation point to the studied area during Typhoon Nakri 1412, August 2014, as shown in Fig. 9.5. At this event, the total rainfall was approximately $640 \mathrm{~mm}$ within $72 \mathrm{~h}$; however, for the studied area, $48 \mathrm{~h}$ is more suitable as a design rainfall duration, because the main part of consecutive rainfall in this event was observed from 6:00 on August 2 to 5:00 on August 4. Consequently, the annual maximum rainfall in $48 \mathrm{~h}$ of $590.5 \mathrm{~mm}$ recorded during that time was selected. In addition, probability analysis was conducted using 45 annual maximum 48-h rainfall data recorded the same observation point. The results of the probability analysis ( $\operatorname{LogP} 3)$ are shown in Table 9.2. As an input for the simulation, the shape of the hyetograph was identical 


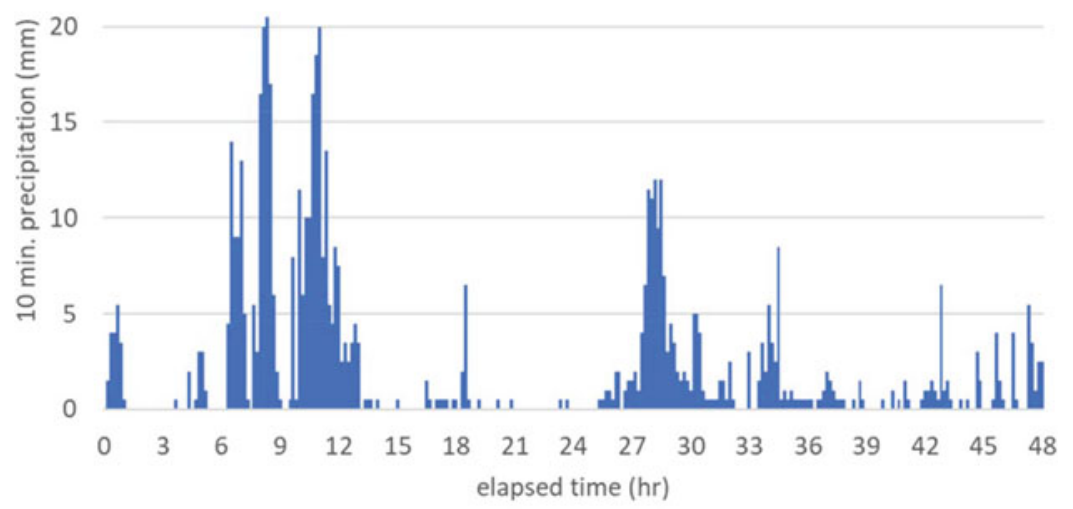

Fig. 9.5 The original hyetograph (recorded in Typhoon 1412, August 2014)

Table 9.2 Probability analysis of $48 \mathrm{~h}$ precipitation ( $\log \mathrm{P} 3)$

\begin{tabular}{l|l|l}
\hline Return period (year) & Total precipitation $(\mathrm{mm})$ & Magnification ratio \\
\hline 2 & 332.0 & 0.56 \\
\hline 5 & 443.8 & 0.75 \\
\hline 10 & 508.5 & 0.86 \\
\hline 20 & 564.5 & 0.96 \\
\hline 25 & 581.1 & 0.98 \\
\hline 27 (original) & 590.5 & 1.00 \\
\hline 30 & 594.4 & 1.01 \\
\hline 50 & 629.7 & 1.07 \\
\hline 80 & 660.3 & 1.12 \\
\hline 100 & 674.3 & 1.14 \\
\hline 150 & 698.8 & 1.18 \\
\hline 400 & 715.5 & 1.21 \\
\hline 500 & 754.0 & 1.28 \\
\hline 1000 & 765.9 & 1.30 \\
\hline & 801.3 & 1.36 \\
\hline
\end{tabular}

(see Fig. 9.5), but the unit precipitation (for $10 \mathrm{~min}$ ) was uniformly enlarged in accordance with the calculated ratio shown in the table.

Before estimating the flood discharge from the Kaifu River into the studied area, the model hydrograph of river discharge was calculated as follows: first, the peak discharge at a certain probability in the river was estimated using the rational method, with the corresponding probability precipitation as an input. Next, using the stage-discharge curve and the recorded stage hydrograph during Typhoon Nakri, the discharge hydrograph was worked out at the upstream boundary of the 2-D river flow simulation model, $12.4 \mathrm{~km}$ upstream from the river mouth. Then, a 2-D 
Table 9.3 River discharge conditions at the upstream boundary

\begin{tabular}{l|l|l}
\hline Return period (year) & River discharge $\left(\mathrm{m}^{3} / \mathrm{s}\right)$ & Magnification ratio \\
\hline 27 (original) & 2230 & 1.00 \\
\hline 50 & 2490 & 1.12 \\
\hline 80 & 2600 & 1.17 \\
\hline 100 & 2680 & 1.20 \\
\hline 1000 & 4480 & 2.01 \\
\hline
\end{tabular}

unsteady flow simulation was performed to obtain a stage hydrograph at an arbitrary levee breaching point. The peak discharge at the upstream boundary was changed in accordance with the required probability precipitation; however, the shape of the hydrograph was fixed, just enlarging the unit discharge. Table 9.3 summarises the peak discharges at the upstream boundary. Since the studied area is located close to the sea, the water stages in both the Kaifu and Zenzo rivers are affected by tidal levels. Thus, the water stage recorded at the river mouth of the Kaifu River during Typhoon Nakri was given as the downstream boundary condition.

Levee breaching points were set at $0.4 \mathrm{~km}$ and $1.8 \mathrm{~km}$ from the river mouth, as those were indicated as weak points against floods in the simulation in terms of relation between the levee height and the peak stage during floods. The levee breaching level was set at the record maximum water level (RMWL) as the primary condition. We assumed that river water starts to flood into the adjacent plains when the water stage in the river reaches the given breach level. In addition, two more breaching levels, the design high water level (HWL) and HWL $+0.6 \mathrm{~m}$, were also considered as cases of levee reinforcement. The relation between water stage hydrograph and the three levee breaching levels considered here is schematised in Fig. 9.6. Since RMWL was lower than HWL, breaching at RMWL provides more flooding volume into the studied area than at HWL. The river flooding discharge as an input into the studied area in the inundation simulation was calculated using a modified Homma's formula for overflow (JSCE 1999).

Two inundation scenarios were explored: one considering only surface water flooding and the other river flooding in addition to surface water flooding. In the latter, the probability of precipitation for river discharge estimated by the aforementioned method and that for surface water flooding was set identically.

\subsection{Results and Discussions}

\subsubsection{Model Verification}

In order to check whether the model could adequately reproduce an actual inundation event, model verification was performed with the inundation records in Typhoon Nakri. The given precipitation hyetograph is shown in Fig. 9.5. Table 9.4 


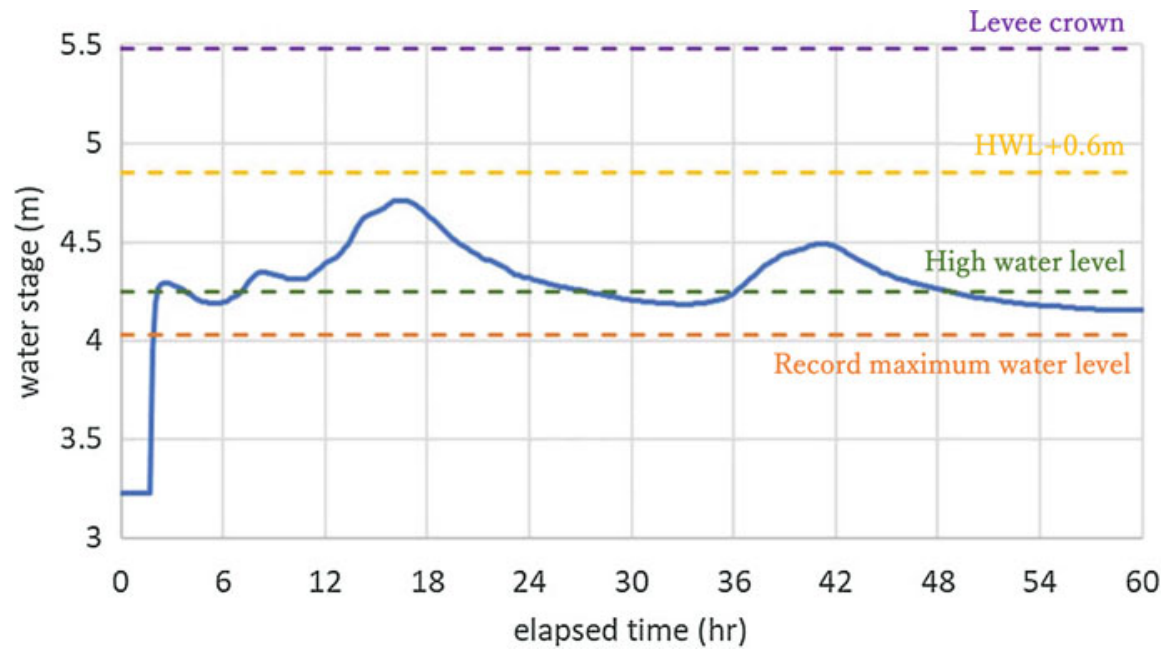

Fig. 9.6 A schematic image of water stage hydrograph and levee breaching levels

Table 9.4 Model

verification: error analyses for the point depths

\begin{tabular}{l|l|l|l}
\hline Point no. & \multicolumn{2}{|l|}{ Maximum inundation depth $(\mathrm{m})$} & Errors $(\mathrm{m})$ \\
\hline & Observation & \multicolumn{2}{l}{ Simulation } \\
\hline 1 & 0.2 & 0.21 & +0.01 \\
\hline 2 & 0.7 & 0.69 & -0.01 \\
\hline 3 & 0.3 & 0.25 & -0.05 \\
\hline 4 & 0.3 & 0.21 & -0.09 \\
\hline 5 & 0.2 & 0.20 & \pm 0 \\
\hline 6 & 0.8 & 0.72 & -0.08 \\
\hline 7 & 0.8 & 0.88 & +0.08 \\
\hline 8 & 0.4 & 0.32 & -0.08 \\
\hline 9 & 0.3 & 0.37 & +0.07 \\
\hline 10 & 0.4 & 0.36 & -0.04 \\
\hline 11 & 0.4 & 0.42 & +0.02 \\
\hline 12 & 0.6 & 0.62 & +0.02 \\
\hline 13 & 0.2 & 0.22 & +0.02 \\
\hline & & &
\end{tabular}

shows a comparison between the water depths read from the flood marks at 13 points in the field (see Fig. 9.7) and the simulation results. The table shows that the errors were less than $10 \mathrm{~cm}$ at all points, and their average was $1 \mathrm{~cm}$, which indicates that the model shows quite high reproducibility. 


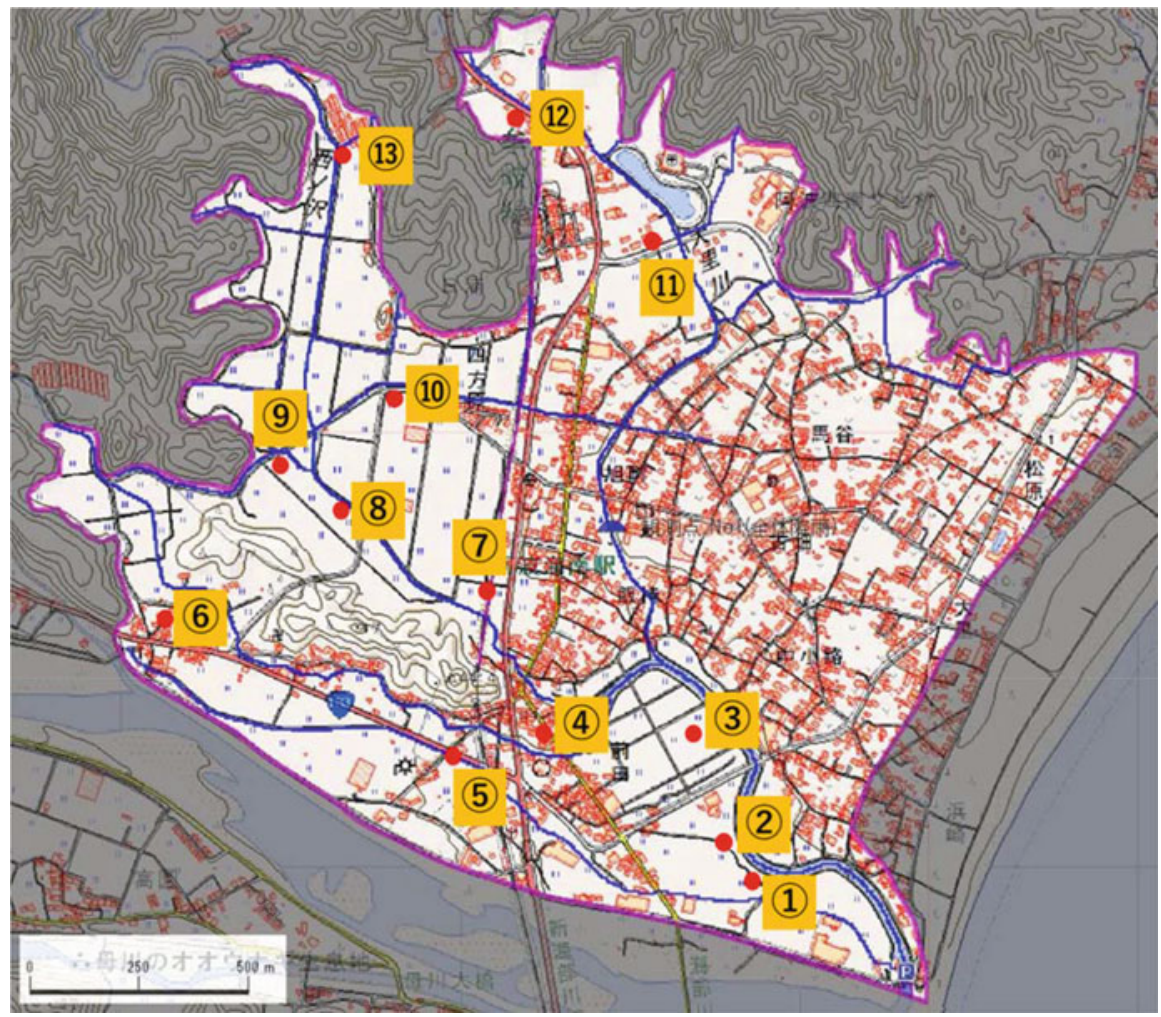

Fig. 9.7 The locations of inundation depth verification

\subsubsection{Surface Water Flooding}

Figure 9.8 shows the relationship between the return period of total precipitation and the peak inundation volume for surface water flooding. The dotted line shows their regression. The relation considering the logarithm of the return period shows almost linear.

Figure 9.9 shows inundation depth distributions at the peak volume for various return periods. As shown in the figure, the depth gradually increases as the return period increases; however, the inundated area does not considerably spread. Referring to the land-use classification in Fig. 9.3, the inundated area consists mostly of paddy fields. In particular, the southern part along the downstream of Zenzo River and the western part around the Nishinosawa River start to be inundated even in a high frequent flood like a 2-year return period. Most of the flooding water remains within paddy fields in these parts even in low frequent floods. 


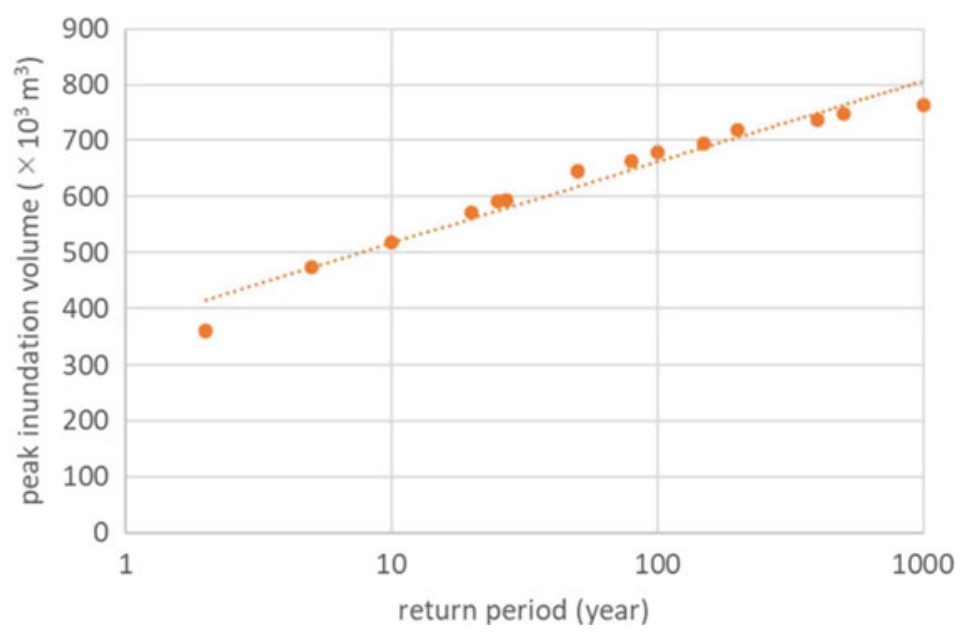

Fig. 9.8 The relationship between the return period of total precipitation and the peak inundation volume for surface water flooding

Figure 9.10 shows the relation between the return period of total precipitation and the area of buildings inundated above floor level. Here inundation above floor level is defined as the water depth on a building mesh over $45 \mathrm{~cm}$. Similar to the relation between the return period and the inundation volume shown in Fig. 9.8, a linear function can be drawn for the inundated buildings. Nevertheless, its ratio to the total building area, $48.2 \mathrm{ha}$, is utmost $3.1 \%$ among the studied cases. This can also be recognised in Fig. 9.11, where locations of the inundated buildings are shown. The figure shows that most of the inundated buildings suffer from 2-year return period flooding, and the number of buildings dose not considerably increase as the return period increases. In other words, only a quite limited amount of buildings is damaged by surface water flooding in the studied area.

Figures 9.12 and 9.13 show the distributions and ratio of damaged paddy fields in response to the precipitation return period, respectively. Here, the threshold of damaged/non-damaged is defined as the water depth $30 \mathrm{~cm}$. Although the number of damaged paddy fields becomes larger as the return period increases, from $25 \%$ to $50 \%$, they are located within a limited area, mainly around the Nishinosawa River and the upstream of Osato River. Referring to the land elevation in Fig. 9.2, those areas are identical to the lower area. In such areas, lots of endangered hygrophytes can be found (Muto et al. 2020). It should be stressed that $25 \%$ of the paddy fields are damaged even in a high frequent flood like 2-year return period.

Figure 9.14 shows the estimated inundation volumes stored only in the paddy fields, plotted as a function of the total inundation volume at its peak. The graph shows that the paddy fields retain $64 \%$ of the inundation volume, and this value is nearly constant over the tested return period. 

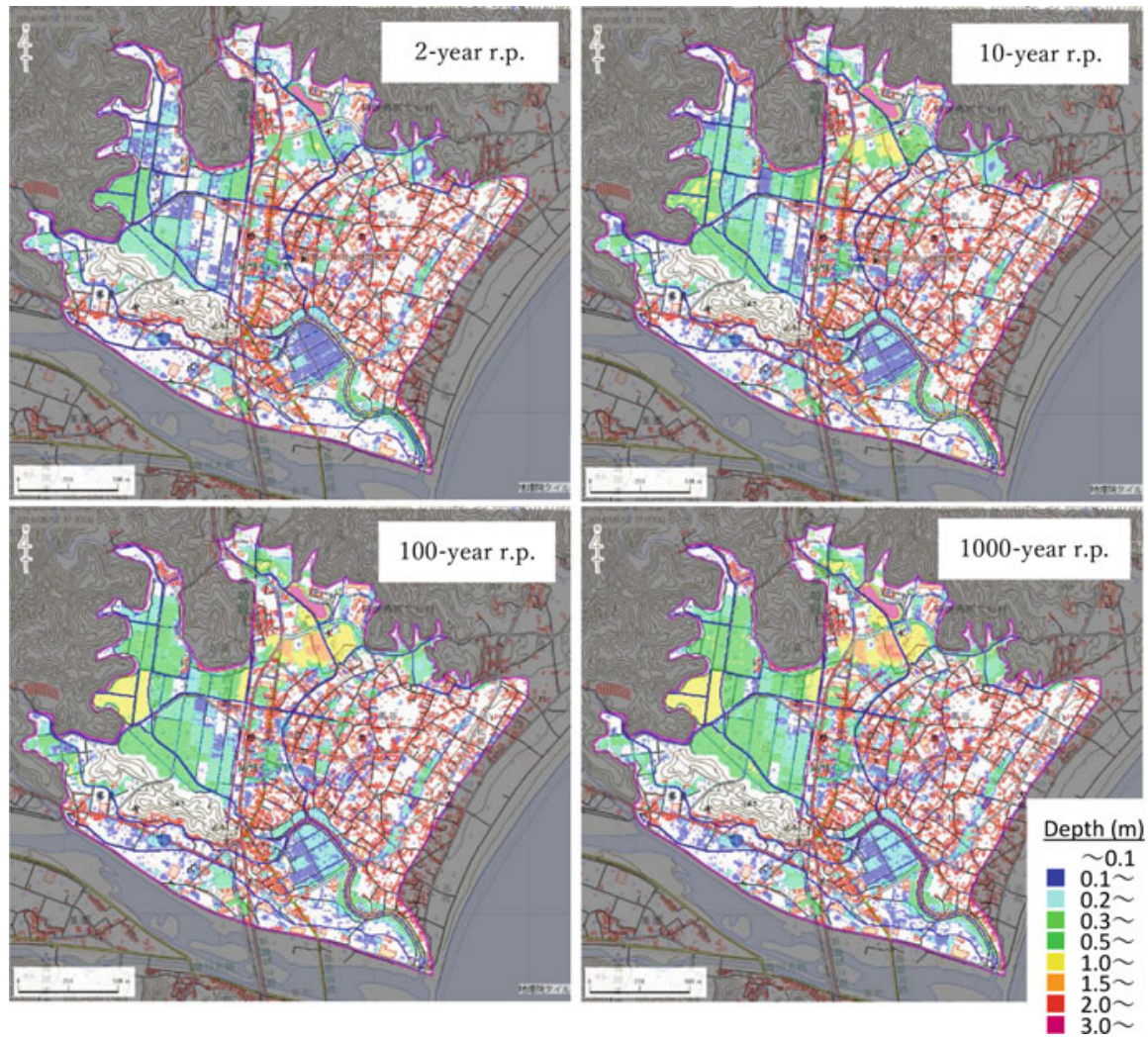

Fig. 9.9 The depth distributions at the peak inundation volume for surface water flooding

\subsubsection{River Flooding Combined with Surface Water Flooding}

Figure 9.15 shows the relation between the return period of total precipitation and the peak inundation volume for the river flooding combined with surface water flooding. Here the breaching level was set at RMWL, and the results for the surface water flooding are also plotted. The dotted lines in the figure indicate tendencies. By adding the river flooding, the inundation volume drastically increases compared with the surface water flooding only. In addition, the inundation volume is different as the breaching point changes. In this study, flooding from $1.8 \mathrm{~km}$ supplies more inundation volume than from $0.4 \mathrm{~km}$. Thus, in sequence, the results shown are mainly for breaching at $1.8 \mathrm{~km}$.

Figure 9.16 shows the inundation depth distributions at the peak volume for various return periods. In the figure, the breaching point is denoted by red X. Considering the depth distribution only for surface water flooding shown in Fig. 9.9, the combined flooding in a 50-year return period matches as the surface water flooding in a 1000-year return period regarding inundated area and depths. This 


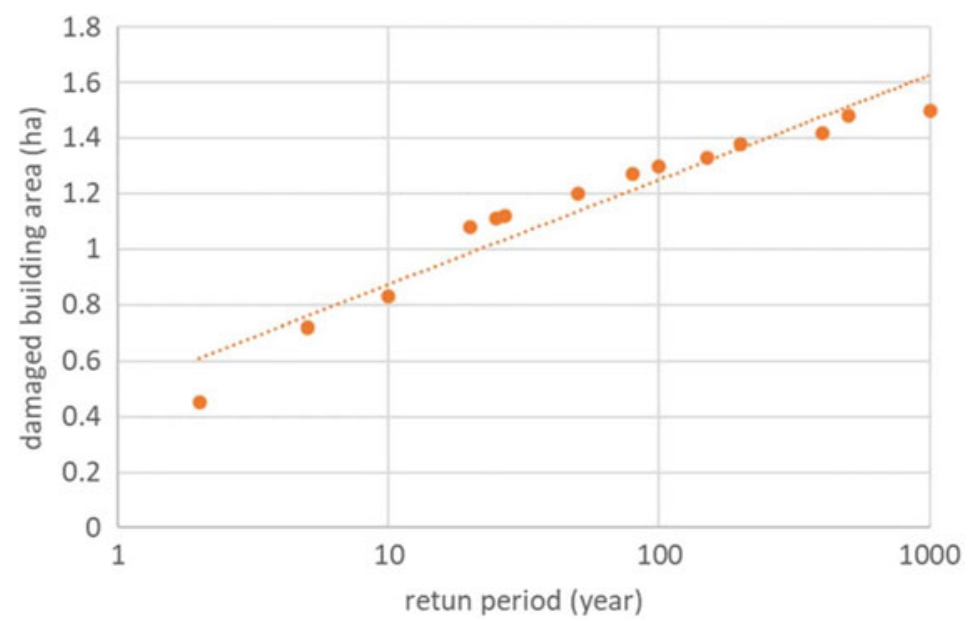

Fig. 9.10 The relation between the return period of total precipitation and the area of buildings inundated above floor level for surface water flooding

can also be seen in Fig. 9.15, where the peak inundation volumes are more or less similar, $700 \times 10^{3} \mathrm{~m}^{3}$. As the precipitation return period increases, the inundation depth initially increases gradually, and then both depth and inundated area largely increase from 100-year to 1000-year return period. Such expansion of inundation is influenced by the breaching point location. When comparing the same return period, breaching at $1.8 \mathrm{~km}$ causes more severe flooding damage than at $0.4 \mathrm{~km}$. This is probably due to not only larger flooding volume (see Fig. 9.6) but wider spreading flooding water because breaching occurs upstream.

In order to estimate the depth increment due to river flooding only, the inundation depth due to surface water flooding, shown in Fig. 9.9, was subtracted from the depth by combined flooding, as shown in Fig. 9.16, in each mesh, that is:

$$
H_{r f}=H_{c f}-H_{s f}
$$

where $H_{r f}$ is the depth increment attributed solely to river flooding and $H_{c f}$ and $H_{s f}$ are the maximum water depths in each mesh in combined and surface water flooding, respectively. The distributions of $H_{r f}$ for various return periods are shown in Fig. 9.17. Not surprisingly, the area near the breaching point shows large increments. By using $H_{r f}$, the expanding process of the inundated area in accordance with the return period becomes clearer. For example, the downstream of the Zenzo River is also extensively affected, although apart from the breaching point to some distance. This indicates that the flooding water from $1.8 \mathrm{~km}$ point runs easterly between the Kaifu and Zenzo rivers. Another interesting feature is that paddy fields in the western and northern parts take charge of floodwater through the three streams. At least up to 100-year return period, floodwater remains within the paddy fields, except for the area near the breaching point. However, in the 1000-year return 


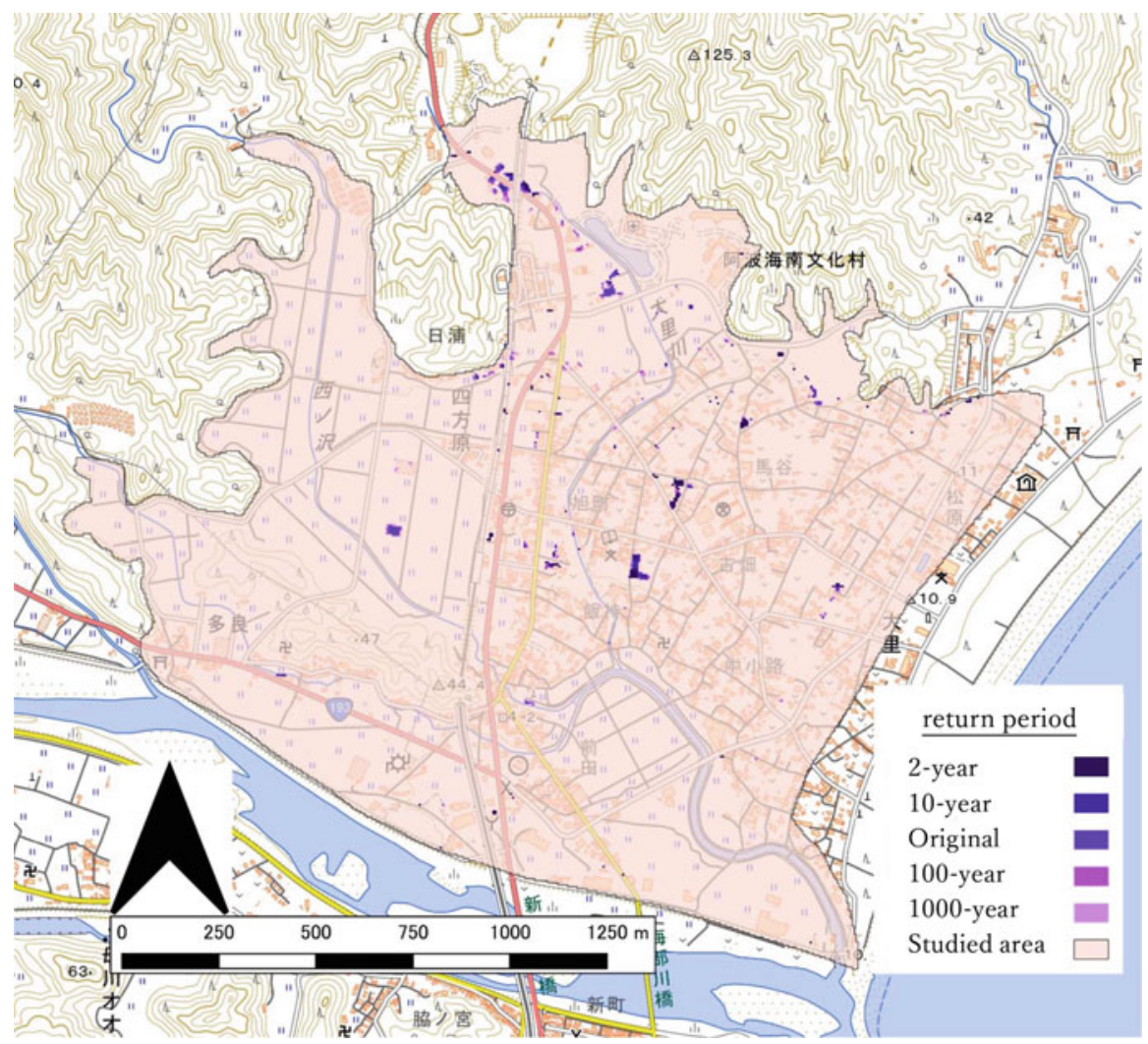

Fig. 9.11 The locations of buildings inundated above floor level in response to the precipitation return period for surface water flooding

period, the inundated area spreads devastatingly, and the maximum depth increment reaches up to 3-4 m near the downstream end of the studied area.

Figure 9.18 shows the relationship between the return period of total precipitation and the area of buildings inundated above the floor level. Similar to the peak inundation volume in Fig. 9.15, the number of inundated buildings increases drastically in the combined flooding. Figure 9.19 shows the locations of the inundated buildings. As shown in the figure, the number of inundated buildings increases gradually as the return period increases. In addition, there are inundated buildings even in the central part including the town office and railway station. In the worst case, the ratio of inundated buildings reaches $46.3 \%$. Such an expanding process of the damaged area is well coincident with the expansion of the inundated area mainly attributed to river flooding, as shown in Fig. 9.17.

Figures 9.20 and 9.21 show the distributions and ratio of damaged paddy fields in response to the precipitation return period, respectively. As shown in these figures, the ratio of damaged paddy fields in combined flooding is fairly higher than that in 


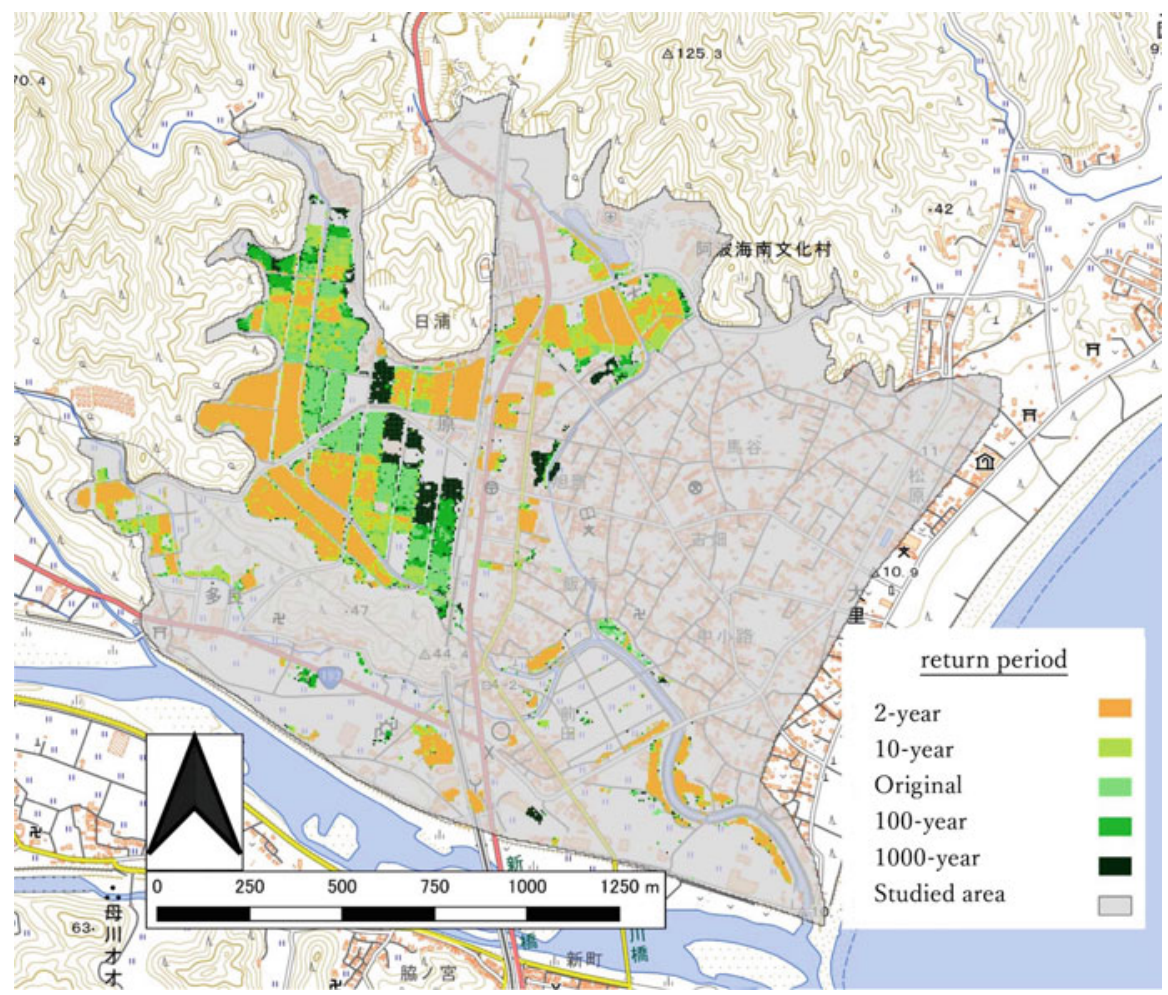

Fig. 9.12 The distributions of damaged paddy fields in response to the precipitation return period for surface water flooding

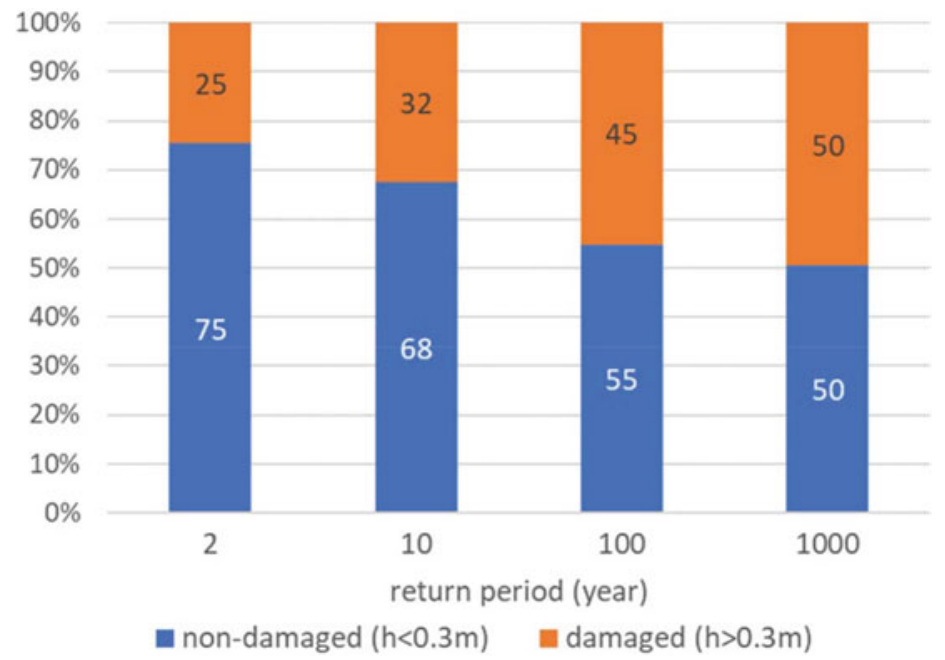

Fig. 9.13 The ratio of damaged/non-damaged paddy fields for surface water flooding 


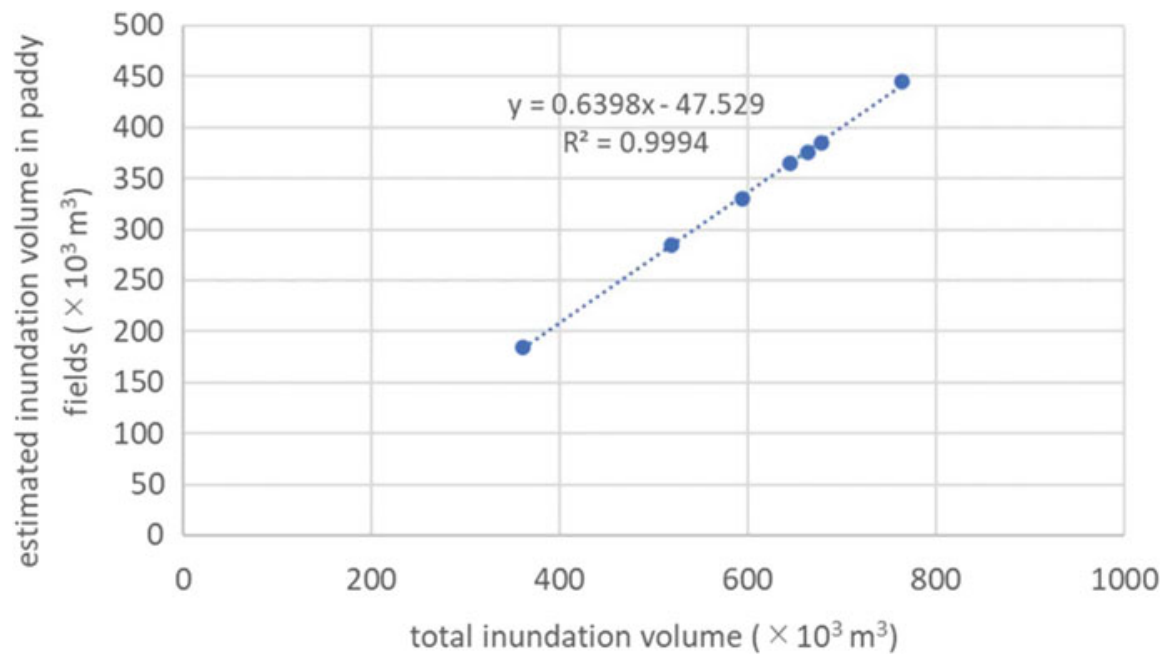

Fig. 9.14 The estimated inundation volume stored in the paddy fields for surface water flooding

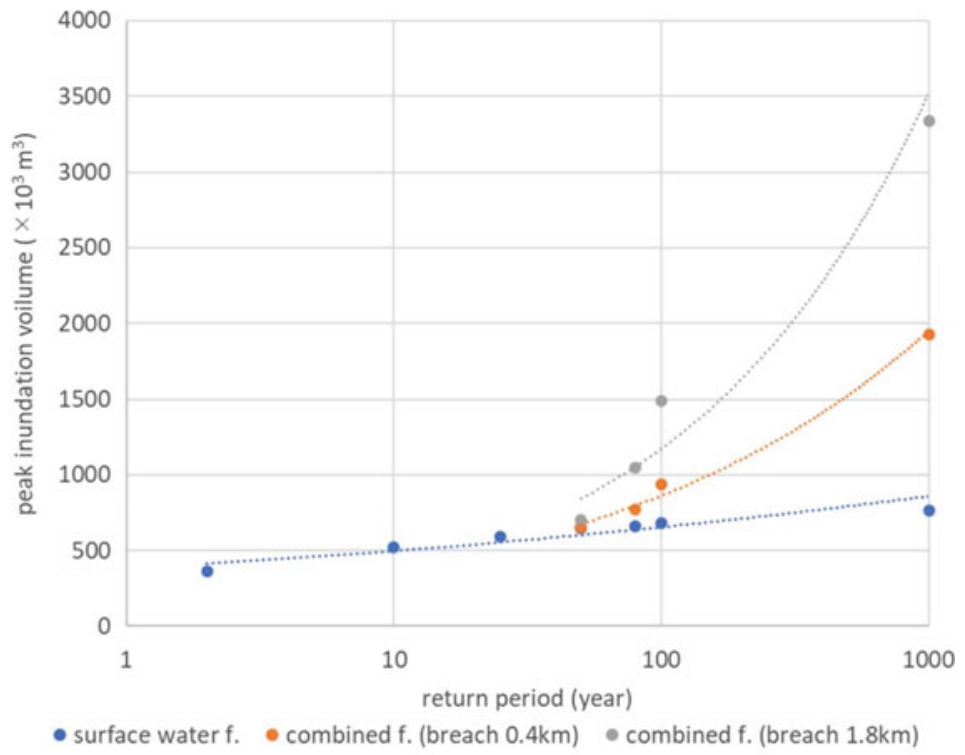

Fig. 9.15 The relation between the return period of total precipitation and the peak inundation volume for combined flooding

surface water flooding. The ratio in the 1000-year return period becomes as high as $94 \%$. Comparing Figs. 9.20 and 9.12, in the western and northern parts, the locations of damaged paddy fields are almost the same under a 100-year return period. Consequently, this increment of damaged paddy fields is mainly brought 

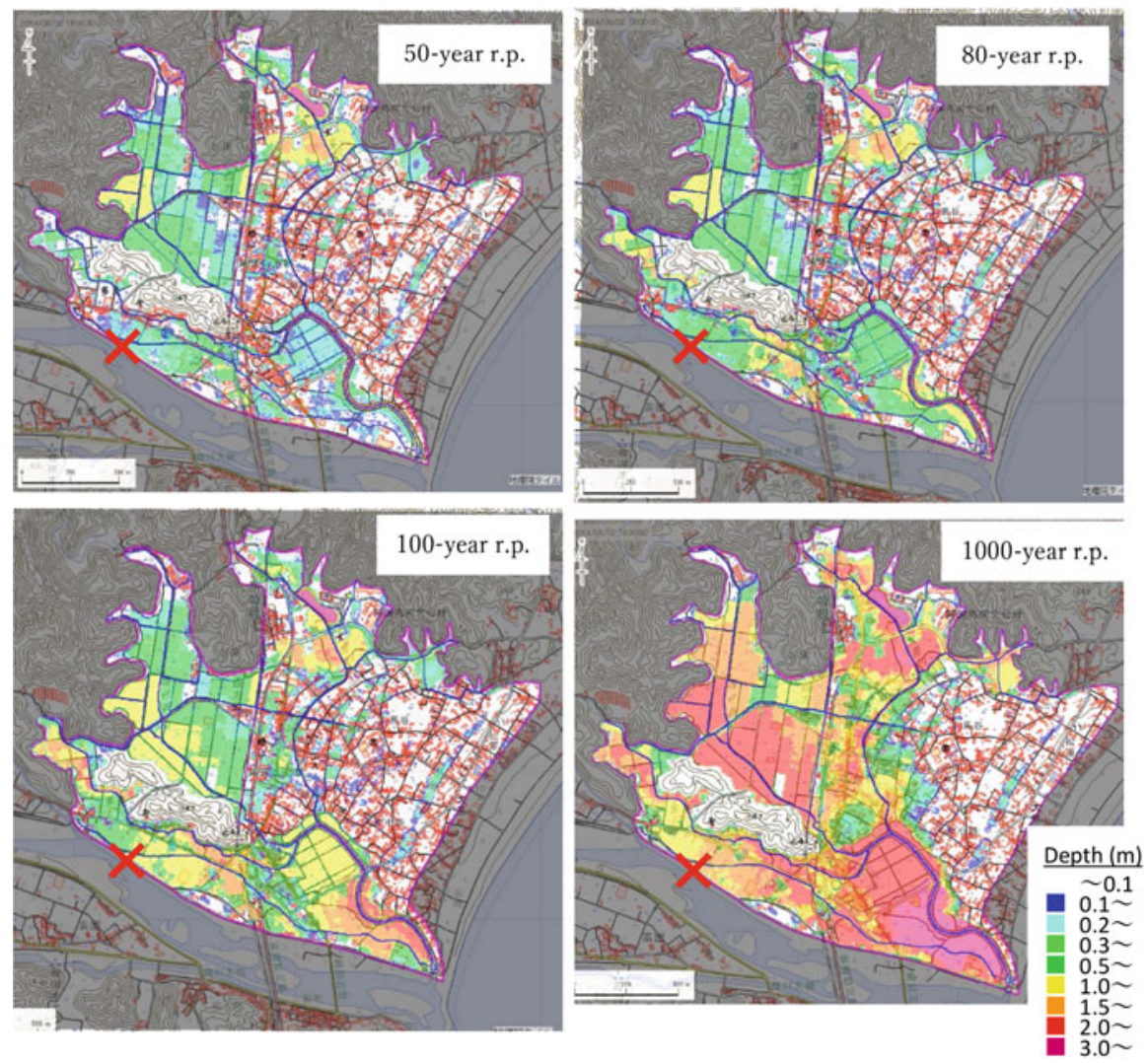

Fig. 9.16 The depth distributions at the peak inundation volume for combined flooding (breaching at $1.8 \mathrm{~km}$ denoted by red $\mathrm{X}$, breaching level at RMWL)

by inundation close to the breach point by river flooding. In the 1000 -year return period, almost all the western and northern paddy fields are damaged.

Figure 9.22 shows the estimated inundation volumes only in the paddy fields, plotted in the same manner as in Fig. 9.14. The graph shows that the paddy fields retain $60 \%$ of the inundation volume for combined flooding, which slightly smaller than that for surface water flooding shown in Fig. 9.14. Again, this value is nearly constant regardless of the return period and breaching point.

\subsubsection{Discussions}

As described in Sect. 9.4.2, for surface water flooding, damaged (inundated above floor level) buildings are quite rare, representing only $3.1 \%$ of the total buildings even in the 1000-year return period. The total inundation volume in the 1000-year 

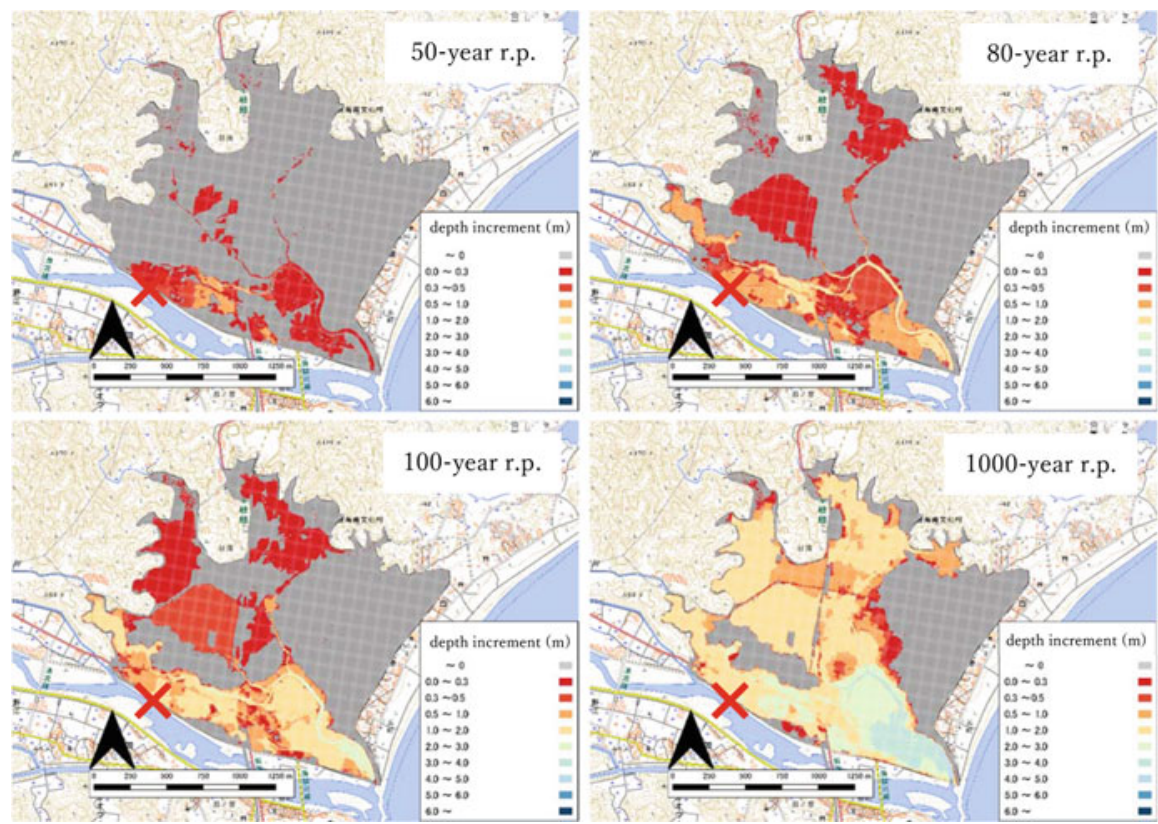

Fig. 9.17 The inundation depth increment due to river flooding onto surface water flooding (breaching at $1.8 \mathrm{~km}$ denoted by red X, breaching level at RMWL)

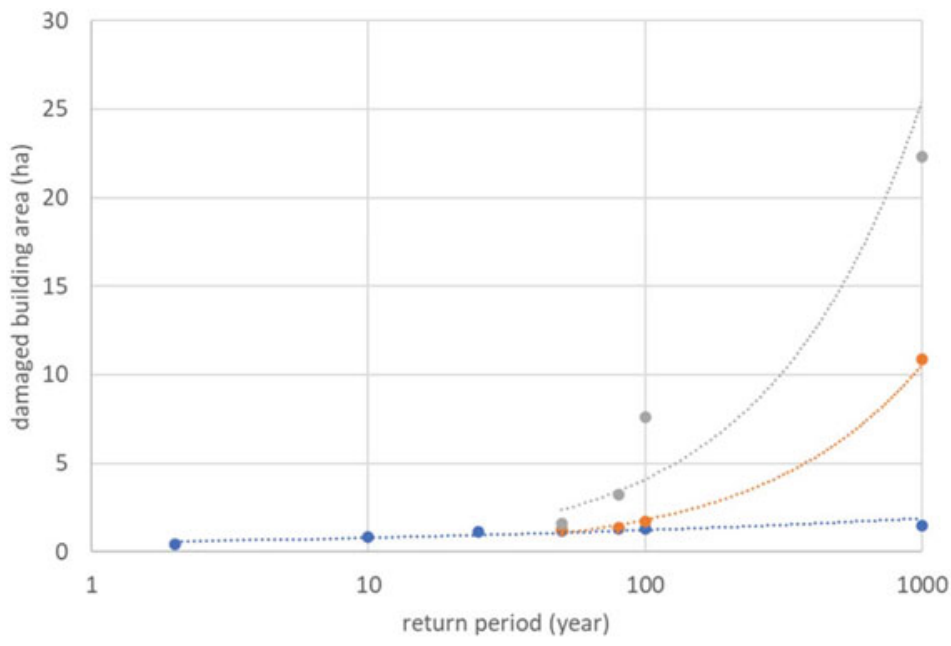

- surface water f. - combined f. (breach $0.4 \mathrm{~km}$ ) - combined f. (breach $1.8 \mathrm{~km}$ )

Fig. 9.18 The relationship between the return period of total precipitation and the area of buildings inundated above floor level for combined flooding 

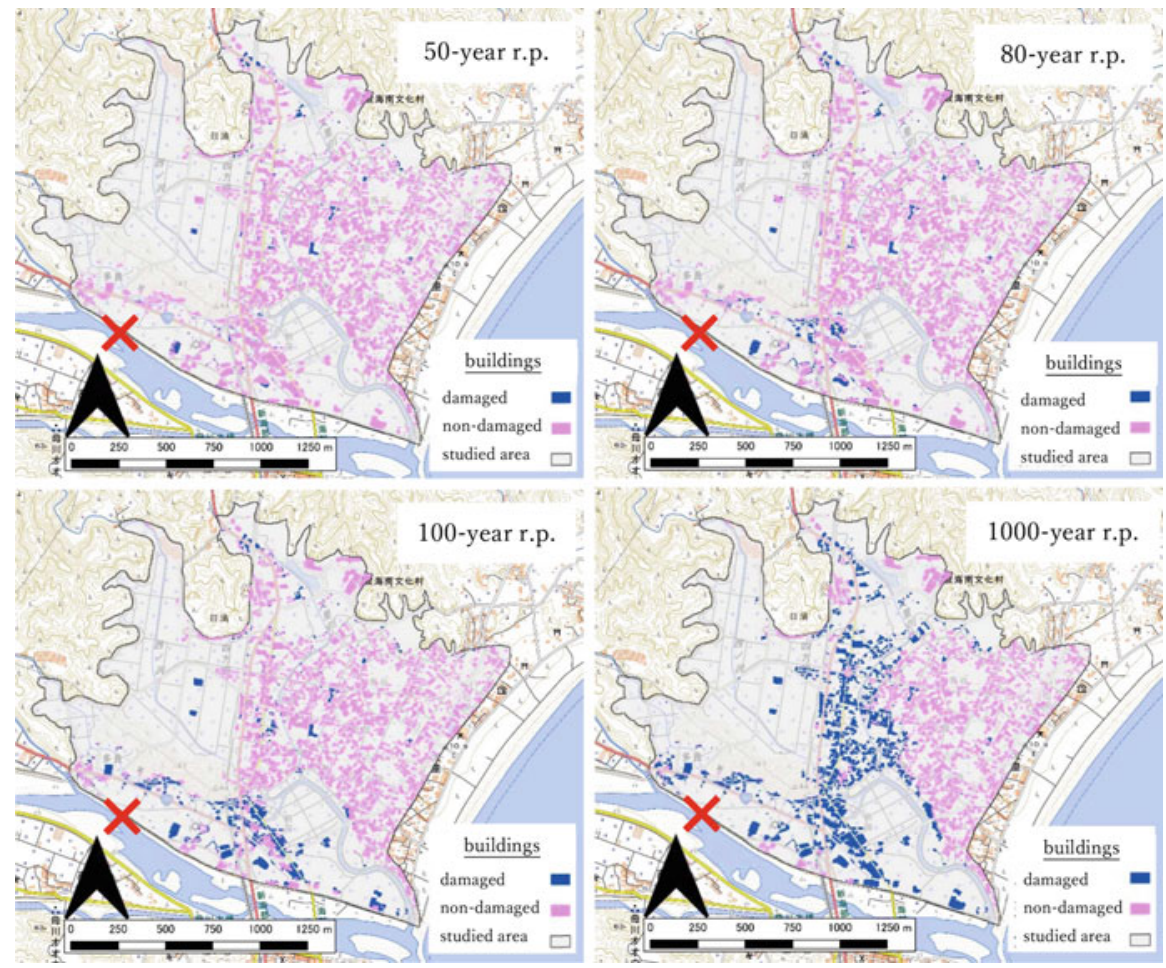

Fig. 9.19 The locations of buildings inundated above floor level for combined flooding (breaching at $1.8 \mathrm{~km}$ denoted by red $\mathrm{X}$, breaching level at RMWL)

return period is approximately $764 \times 10^{3} \mathrm{~m}^{3}$, and $64 \%$ of the volume is allocated to the paddy fields. Although some damaged paddy fields become apparent, disaster risk directly affecting mankind is still low. In other words, paddy fields secure human lives and properties by retaining most of the flooding volume. In the studied area, as a result, the current land-use classification can make sense in terms of disaster risk reduction against surface water flooding.

For river flooding combined with surface water flooding, as shown in Sect. 9.4.3, flooding from the river increases the inundated area and depth. However, the floodwater is primarily deposited in the vicinity of the breaching point, and in the western and northern paddy fields through the streams, surprisingly a bit far from the breach point. The studied area again can retain the floodwater volume to remain human risk relatively low, up to 80 - to 100 -year return period for combined flooding. In addition, the area between the Kaifu and Zenzo rivers is mainly used as paddy fields, directly receiving the floodwater from the river; thus, it can store the floodwater without increasing the threat to human lives to some extent. This should also be appreciated as a wise example of land use against floods. 

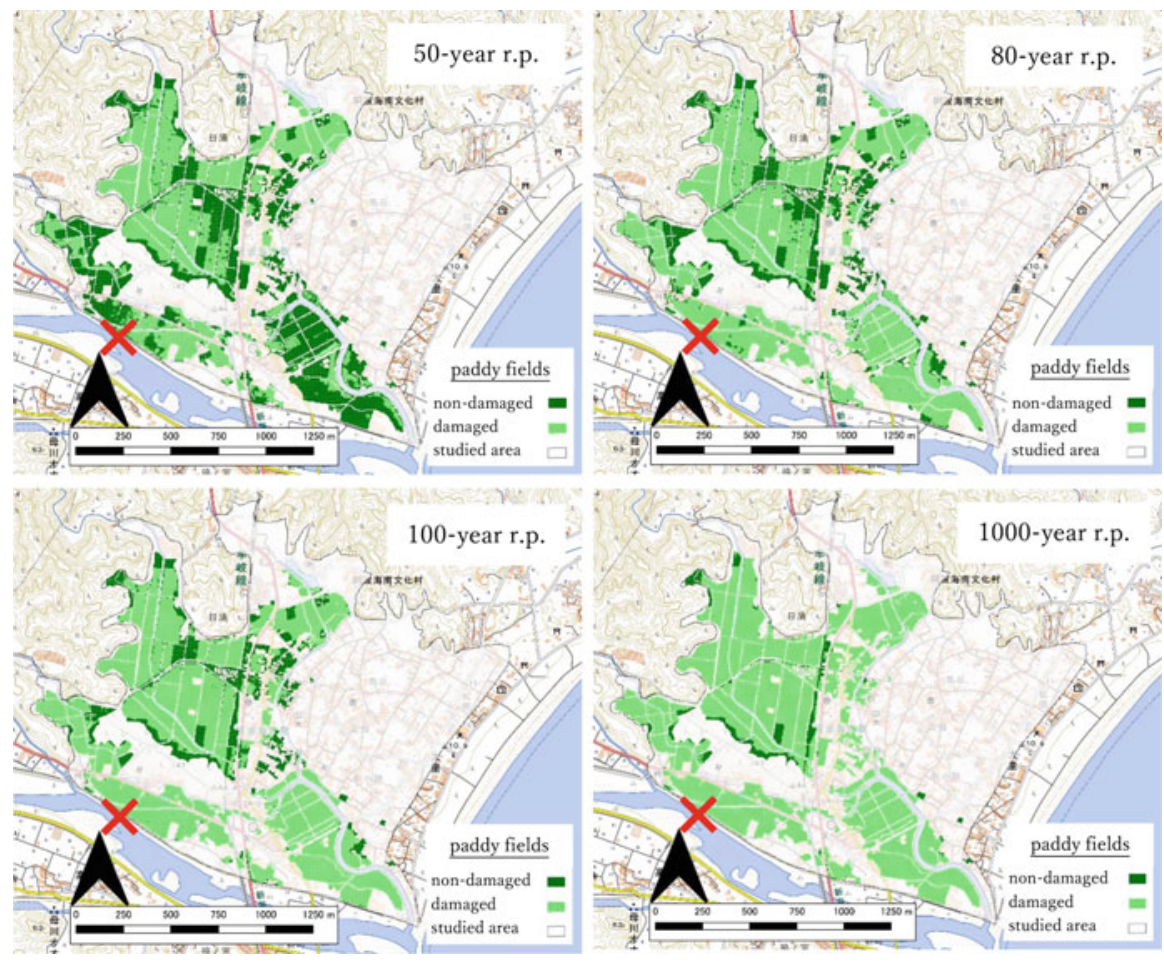

Fig. 9.20 The distributions of damaged paddy fields for combined flooding (breaching at $1.8 \mathrm{~km}$ denoted by red X, breaching level at RMWL)

Under a quite low-frequency event such as a 1000-year return period, damage to housing areas in the eastern part, mainly on high sand dunes along the beach, is inevitable. As mentioned above, inundation in the studied area starts from the southern (near the river), western and northern (paddy fields) parts, then it spreads from these three directions toward the central part as the precipitation becomes larger, and finally the relatively high eastern part gets inundated. Here, we can consider two reference values regarding damages: one is when a building in the central part near the town hall gets inundated and the other does other buildings on the higher sand dune. The former is recognised as damage to buildings starts to expand, and the latter is considered as seriously enlarge damage by inundating the residential area on high and relatively safer parts. Figure 9.23 shows the calculated inundation volumes only in the paddy fields plotted as a function of the return period, together with the locations of these two reference values. Judging from the simulation results, the former lies within $80-(1.8 \mathrm{~km}$ breaching $)$ and $100-(0.4 \mathrm{~km}$ breaching) year return periods, indicated with a blue band in the figure, whereas the latter lies over a 100-year return period, shown as a green band. By doing this, we can estimate the potential volume of floodwater that can be retained by the paddy 


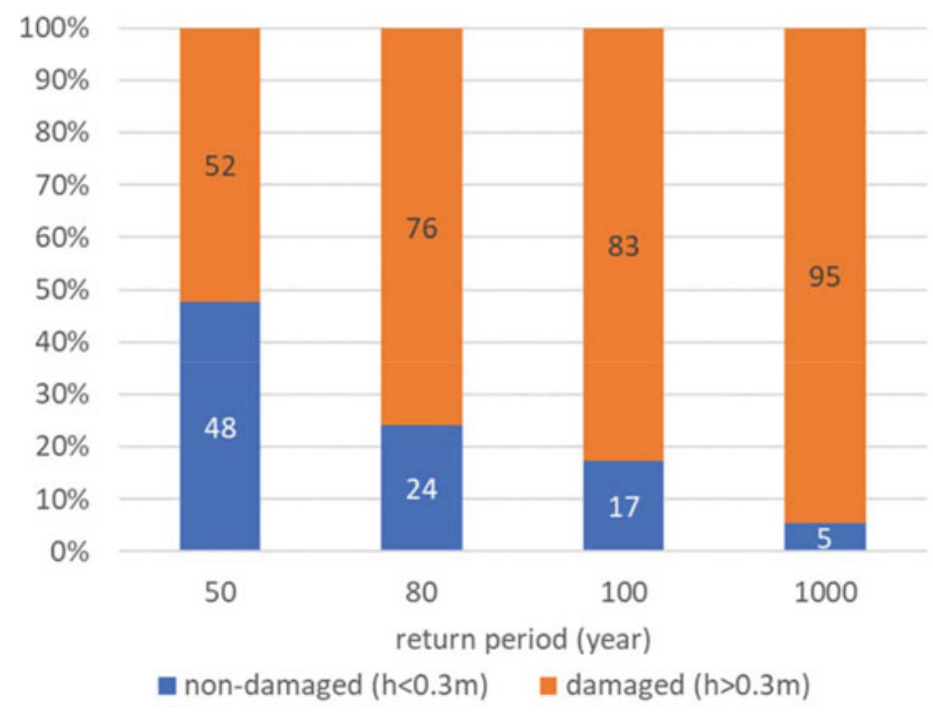

Fig. 9.21 The ratio of damaged/non-damaged paddy fields for combined flooding (breaching at $1.8 \mathrm{~km}$, breaching level at RMWL)

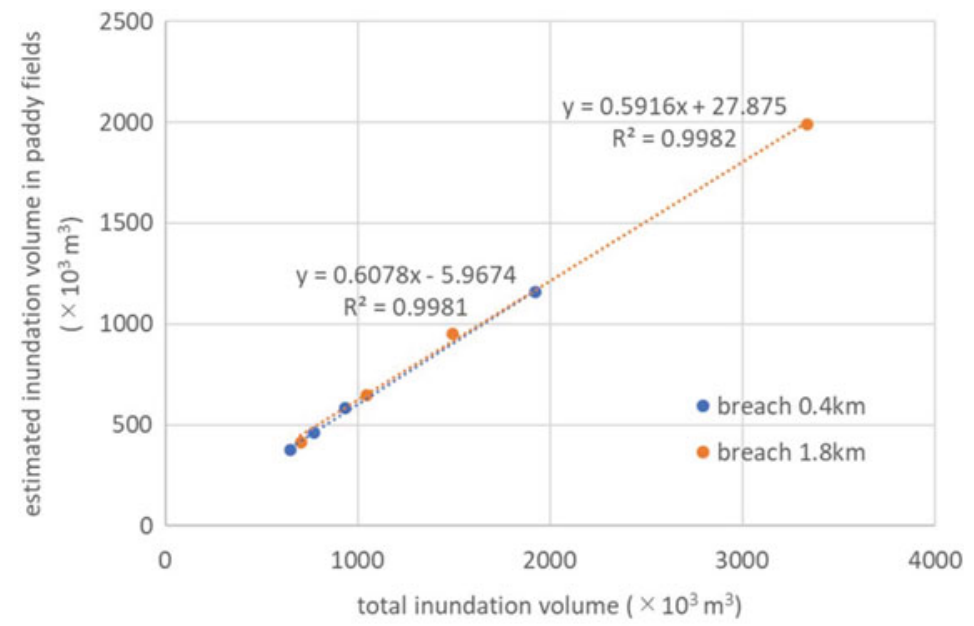

Fig. 9.22 The estimated inundation volume stored in the paddy fields for combined flooding

fields until damage to buildings and houses starts to occur. From the figure, the paddy fields in the studied area can retain 590 to $640 \times 10^{3} \mathrm{~m}^{3}$ of floodwater before damage starts to expand in the central part, and of 950 to $1150 \times 10^{3} \mathrm{~m}^{3}$ of floodwater before huge damage occurs in the eastern part. The figure can also be used to explain why damage to buildings is small for surface water flooding. 


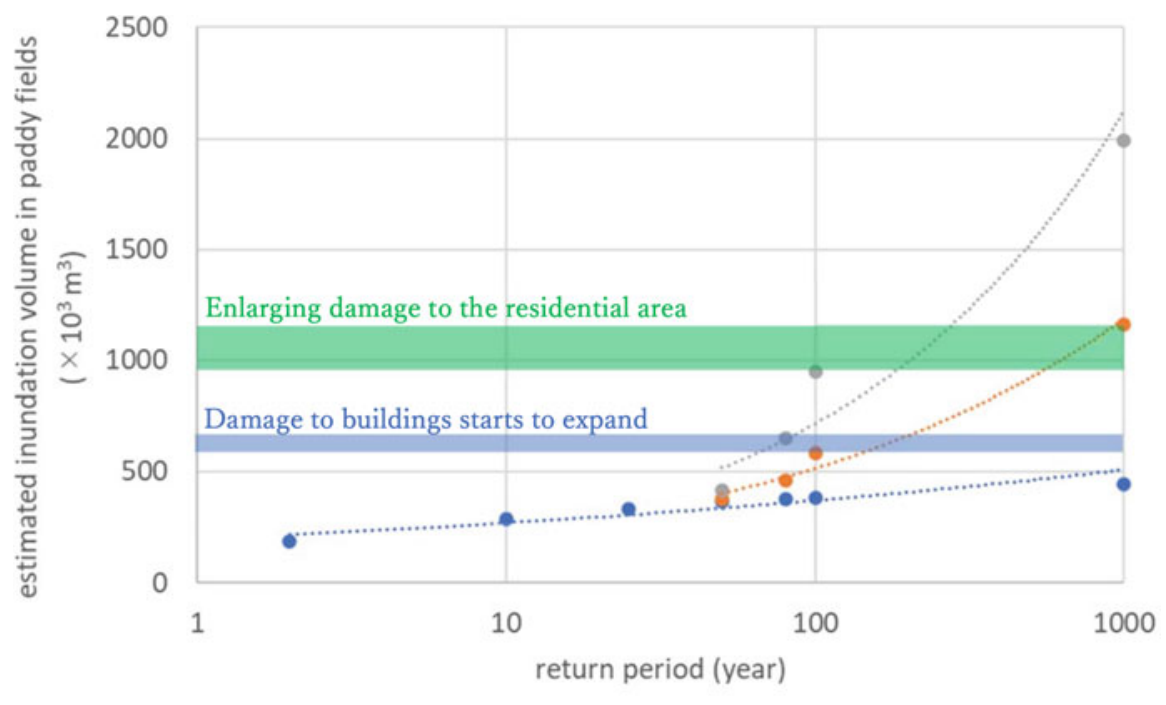

- surface water f. - combined f. (breach 0.4km) - combined f. (breach $1.8 \mathrm{~km}$ )

Fig. 9.23 Two reference values regarding damage to buildings with reference to the estimated inundation volumes in the paddy fields

Considering the expanding process of floodwater together with the two reference values described above, it is important to secure the buildings in the central part, which start to be inundated between two reference levels. If these buildings are protected in some ways, a critical inundation volume in which damage to buildings starts can be enlarged. One of traditional methods is levee reinforcement. Figure 9.24 shows how much levee reinforcement reduces damaged buildings. Here three additional breaching scenarios, changing the breaching level at (1) HWL, (2) HWL $+0.6 \mathrm{~m}$ and (3) at the same breaching level (RMWL) but overflow starting from the hydrograph peak, were explored for a 1000-year return period. The third condition is supposed to reinforce the levee in some ways, to avoid breaching immediately after reaching the setting level and to endure against flow until the hydrograph peak. The figure indicates that these levee reinforcements are all effective since they can reduce the total flooding volume. From the viewpoint of hybrid infrastructure, that is, the best matching of grey and green infrastructures, such considerations will be useful to seek how much risk the grey should take. On the other hand, because the levee reinforcement does not change alluvial plains and their drainage system at all, once flooding exceeds a certain level and pours into the plains, the same expansion process of flood flow as without levee reinforcement will be reproduced. Rather, in order to make full use of the flood control function of paddy fields, it would be better to consider land-use alteration, including building transference and wetland restoration. By doing this, the potential 

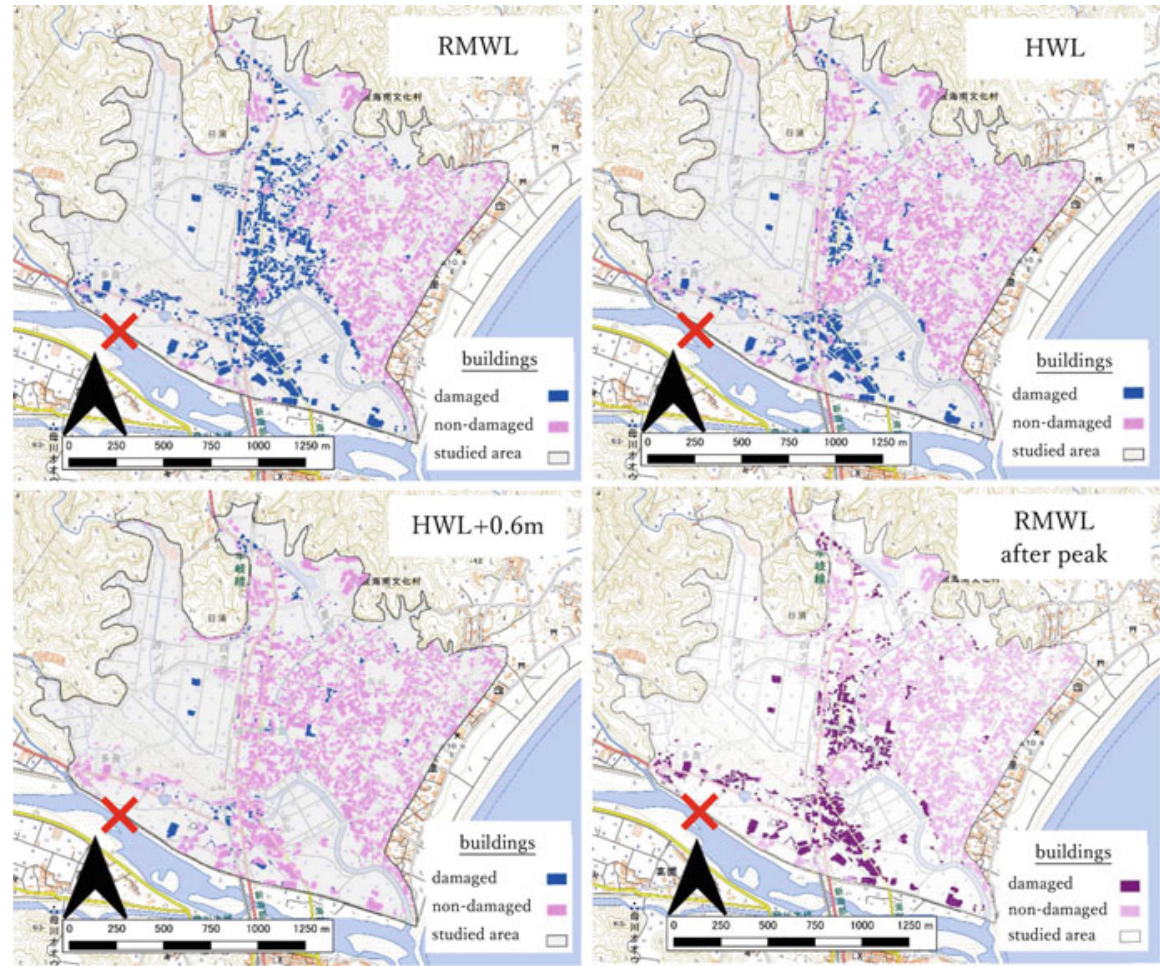

Fig. 9.24 The effect of the breaching level on locations of damaged buildings for combined flooding (1000-year return period, breaching at $1.8 \mathrm{~km}$ denoted by red $\mathrm{X}$ )

volume of floodwater retention in paddy fields can be extended at least up to the green band level, which well meets the concept of green infrastructure.

\subsection{Concluding Remarks}

By performing the inundation simulation, not only the potential storage volume but the expanding process of inundation in the studied area can be clarified. This also provides insights into the advantage of current land-use towards flooding, and leads to present a land-use strategy to be in the future against low-frequency floods.

Our recommendation for future land use is to transfer the buildings from the vulnerable central part to floods and to turn it back to the wetland. This may sound to require considerable efforts; however, with reference to a past aerial photo shown in Fig. 9.25, this part used to be mainly utilised as paddy fields. The potential volume of floodwater retention in paddy fields in the studied area should presumably be larger in the past. This can be a good reference for considering land-use strategies. 


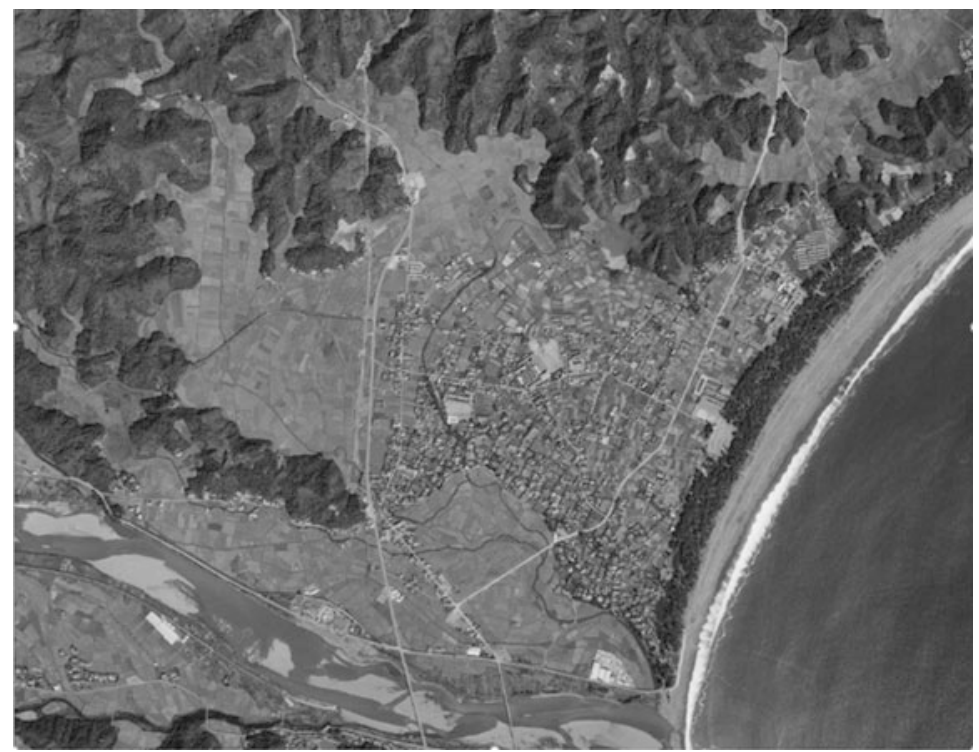

Fig. 9.25 An aerial photo of the studied area in the mid-1960s

Recently, Watanabe and Muto (2021) also confirmed the advantage of building transfer from the central part, from the viewpoint of town planning.

We do not take a position criticising the current land use, since it has been realised as a result of various factors, such as population growth, high economic growth, technological innovation against floods and so on. These factors sometimes allowed, and sometimes pushed, to move residential areas onto low and vulnerable parts. Nevertheless, the tendencies have now changed, particularly regarding the population. We can now do manage to live outside the vulnerable area. It must be a good time to consider withdrawing from the risk exposure.

In this study, we do not quantify damage to inundated paddy fields, but we intend to maximally utilise their flood retention capacity to reduce damage in residential areas as the most important aspect. However, this concept will make controversy among the concerned persons. To realise our proposal, not only explaining its economic advantages but consensus building is crucially important.

\section{References}

Iwasa Y, Inoue K (1982) Mathematical simulation of channel and overland flood flows in view of flood disaster engineering. J Nat Dis Sci 4(1):1-30

Japan Society of Civil Engineers (edited and published) (1999) Formulary of Hydraulics. 713 pp. (in Japanese)

Kusaka M (2020) Plains and Japanese history. Kadokawa. 209 pp. (in Japanese) 
Masumoto T (1998) Paradigm shift in the evaluation of water storage function of paddies and in watershed management. J Japan Soc Hydrol Water Res 11(7):711-722. (in Japanese)

Ministry of the Environment, Japan (2016) Ecosystem-based disaster risk reduction in Japan. In: A handbook for practitioners. $24 \mathrm{pp}$

Miyazu S, Yoshikawa N, Abe S, Misawa S, Yasuda H (2012) Development of application of evaluation model for interior flood damage mitigation effect of a paddy field dam. IDRE J 282:15-24. (in Japanese)

Muto Y, Imai Y, Kamada M (2020) Ecosystem services of paddy fields and basinwide comprehensive flood alleviation. In: Green infrastructure-its practices. Nikkei BP, pp 308-317. (in Japanese)

NITA Consultant Co., Ltd (n.d.) Introduction to AFREL. http://www.nita.co.jp/index.php/ software/afrel. (in Japanese)

Thang NT, Inoue K, Toda K, Kawaike K (2004) A model for flood inundation analysis in urban area: verification and application. Ann Disast Prev Res Inst Kyoto Univ 47B:13 pp

Watanabe K, Muto Y (2021) A study on future land use considering flood disaster in Osato district in Kaiyo Town, Tokushima. In: Proceedings of Awagakkai, no 63, pp 145-153 (in Japanese)

Yoshikawa N, Miyazu S, Koide H, Misawa S, Yasuda H (2010) Evaluation of flood mitigation effect of a paddy field dam in an unimproved paddy field area. Adv River Eng 16:507-512. (in Japanese)

Open Access This chapter is licensed under the terms of the Creative Commons Attribution 4.0 International License (http://creativecommons.org/licenses/by/4.0/), which permits use, sharing, adaptation, distribution and reproduction in any medium or format, as long as you give appropriate credit to the original author(s) and the source, provide a link to the Creative Commons license and indicate if changes were made.

The images or other third party material in this chapter are included in the chapter's Creative Commons license, unless indicated otherwise in a credit line to the material. If material is not included in the chapter's Creative Commons license and your intended use is not permitted by statutory regulation or exceeds the permitted use, you will need to obtain permission directly from the copyright holder. 